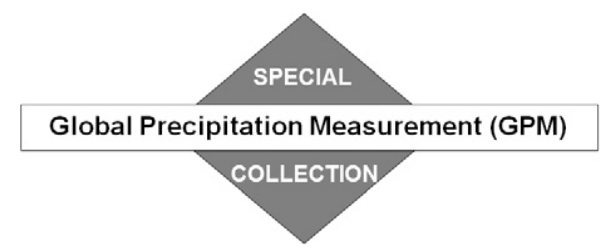

\title{
Evaluation of the Quality of Precipitation Products: A Case Study Using WRF and IMERG Data over the Central United States
}

\author{
JIAYING ZHANG \\ School of Civil and Environmental Engineering, Georgia Institute of Technology, Atlanta, Georgia \\ LIAO-FAN LIN \\ Department of Atmospheric Sciences, University of Utah, Salt Lake City, Utah \\ RAFAEL L. BRAS \\ School of Civil and Environmental Engineering, Georgia Institute of Technology, Atlanta, Georgia
}

(Manuscript received 23 July 2018, in final form 5 October 2018)

\begin{abstract}
Hydrological applications rely on the availability and quality of precipitation products, especially modeland satellite-based products for use in areas without ground measurements. It is known that the quality of model- and satellite-based precipitation products is complementary: model-based products exhibit high quality during cold seasons while satellite-based products are better during warm seasons. To explore the complementary behavior of the quality of the precipitation products, this study uses 2-m air temperature as auxiliary information to evaluate high-resolution $\left(0.1^{\circ} /\right.$ hourly) precipitation estimates from the Weather Research and Forecasting (WRF) Model and from the version 5 Integrated Multisatellite Retrievals for GPM (IMERG) algorithm (i.e., early and final runs). The products are evaluated relative to the reference NCEP Stage IV precipitation estimates over the central United States during August 2015-July 2017. Results show that the IMERG final-run estimates are nearly unbiased, while the IMERG early-run and the WRF estimates are positively biased. The WRF estimates exhibit high correlations with the reference data when the temperature falls below $280 \mathrm{~K}$. The IMERG estimates, both early and final runs, do so when the temperature exceeds $280 \mathrm{~K}$. Moreover, the complementary behavior of the WRF and the IMERG products conditioned on air temperature does not vary with either season or location.
\end{abstract}

\section{Introduction}

Precipitation is a key variable of the hydrologic cycle, and the availability of high-quality precipitation products is important to many hydrologic applications. The most accurate precipitation products are from gauges because precipitation is directly measured. However, products from gauges are subject to random and systematic errors (e.g., wind-induced losses), and they have limited spatial coverage (e.g., Xie et al. 2007; Nazaripour and Daneshvar 2017). On the other hand, ground-based radars provide excellent spatial and temporal resolutions, but they are not globally available either (e.g., Chen et al. 2015; J. Zhang et al. 2016). For applications in regions without ground-based observations, satellite- and

Corresponding author: Jiaying Zhang, jiaying.zhang@gatech.edu model-based products promise to provide better coverage over the globe (Behrangi et al. 2014; Lin et al. 2015). However, the quality of these two types of precipitation products varies seasonally and latitudinally (Junker et al. 1992; Vidale et al. 2003; Villarini and Krajewski 2007; Sapiano and Arkin 2009; Baxter et al. 2014; Yong et al. 2016). Nevertheless, such seasonal and latitudinal variations could be captured by air temperature (Peel et al. 2007; Behrangi et al. 2015; Smalley et al. 2014).

Seasonal and latitudinal variations of the quality of satellite-based precipitation products have been widely investigated. Maggioni et al. (2016) reviewed previous work that evaluates commonly used satellite-based precipitation products across different regions of the world and found that satellite products show large biases during cold seasons associated with light rain, snow, and 
mixed-phase precipitation. In the era of the Global Precipitation Measurement (GPM) mission (Hou et al. 2014), the Integrated Multisatellite Retrievals for GPM (IMERG; Huffman et al. 2015) provide highresolution estimates, but the quality of IMERG products still varies with seasons and climate regions (Khan et al. 2016). For a subtropical region, Sharifi et al. (2016) revealed that the IMERG product has more skill in representing daily precipitation than the post-real-time Tropical Rainfall Measuring Mission (TRMM) Multisatellite Precipitation Analysis (TMPA-3B42) and the ERA-Interim product from the European Centre for Medium-Range Weather Forecasts (ECMWF) in Iran from March 2014 to February 2015. For the midlatitude region of the Ganjiang River basin in southeast China, Tang et al. (2016b) showed that the detection skill of the Day-1 IMERG final-run product is comparable with version 7 near- and post-real-time TMPA-3B42 products during a rainy season from May to September in 2014. Tang et al. (2016a) further evaluated the IMERG finalrun product over mainland China with several subregions representing different latitudes, altitudes, and climates, and they showed that the IMERG product exhibits poor quality in high latitudes. This dependence of quality on latitude and the corresponding ability of temperature in capturing latitudinal variations begs the question of whether temperature could be an indicator of quality.

Complementing satellite precipitation products are those from numerical weather prediction (NWP) models that show good performance at high latitudes and during cold seasons and poor performance at the tropics and during warm seasons (Adler et al. 2001; Gottschalck et al. 2005; Ebert et al. 2007; Kidd et al. 2012). For example, McBride and Ebert (2000) evaluated NWP model precipitation over Australia by dividing the country into southeastern subtropical and northern tropical regimes, and they showed that the model skill is good in the subtropical regime and quite low in the tropical regime. The Working Group on Numerical Experimentation (WGNE) also evaluated precipitation products from several NWP models over the United States and Germany, and they showed that these models are capable of producing high-quality precipitation except for over the tropical regions (Ebert et al. 2003). Siddique et al. (2015) assessed the quality of precipitation products from two NWP models in the mid-Atlantic region of the United States and found that the models exhibit more skill during the cold season than the warm season, and this seasonal variation of the precipitation products does not depend on other factors (e.g., forecast lead times, basin sizes, and precipitation amount). Based on the complementary quality of the satellite- and model-based estimates, many scholars merged information from the two types of precipitation products and improved precipitation estimates (Zhang et al. 2013; Nikolopoulos et al. 2015; X. Zhang et al. 2016; Beck et al. 2017).

The climatology of a region is often characterized by land surface temperatures and other factors (e.g., Peel et al. 2007). Building on the aforementioned literature, we then hypothesize that the quality of model- and satellite-based precipitation products may be directly informed by the surface temperature. To explore such a relationship, we compare high-resolution precipitation data $\left(0.1^{\circ}\right.$ hourly) obtained from the IMERG and the Weather Research and Forecasting (WRF) Model simulations during August 2015-July 2017. The comparison is informed by $2-\mathrm{m}$ air temperature over the central United States. The 2-m air temperature is chosen because it discriminates the type of precipitation (i.e., solid or liquid) reasonably, but in contrast to surface temperature, it is less affected by surface variability. Moreover, it is the most common temperature measurement and commonly used in NWP verification and hydrological applications. Results show that the IMERG estimates are more accurate than the WRF estimates when the temperature is above $280 \mathrm{~K}$, while the reverse is true when the temperature is below $270 \mathrm{~K}$. The rest of this paper is organized as follows. Section 2 describes the precipitation datasets and evaluation methods. Section 3 presents the evaluation of the precipitation products at various time scales with and without the information of temperature. Section 4 discusses the robustness of the results. Section 5 provides conclusions.

\section{Data and methods}

\section{a. IMERG early- and final-run products}

This study uses version 5 IMERG early- and final-run products. The IMERG level 3 multisatellite precipitation product combines precipitation estimates from all passive microwave sensors from the GPM constellation, infrared observations from geosynchronous satellites, and monthly gauge measurements (Huffman et al. 2015). IMERG covers the globe from $60^{\circ} \mathrm{S}$ to $60^{\circ} \mathrm{N}$ with a spatial resolution of $0.1^{\circ}$ and a temporal resolution of $30 \mathrm{~min}$ and has three runs-early, late, and final—with different latency and accuracy. The early run, with a delay of 6 hours, employs morphing techniques that use the information from geostationary infrared data at a fine time scale to fill the gaps in coverage of microwave overpasses (Joyce et al. 2004). The late run, with a delay of 18 hours, allows additional microwave observations to be used in the morphing techniques. Both the early and late runs are adjusted to climatological monthly precipitation values. The final run, with a delay of 4 months, is adjusted to 
calendar monthly gauge measurements. Because the difference between the early- and late-run products is small (O et al. 2017), this study focuses on the early and final runs. The datasets are available on the Precipitation Measurement Missions website (https://pmm.nasa.gov/data-access/ downloads/gpm) and detailed information is given in Huffman et al. (2015).

\section{b. WRF Model simulation}

This study uses the version 3.8 WRF Model to provide precipitation and 2-m temperature simulations. We focus on the central United States to avoid complex terrain, over which precipitation products show poor skills (Chen et al. 2015; Maggioni et al. 2016). The domain is configured with a single domain of $270 \times 220$ grids that have horizontal spacing of approximately $10 \mathrm{~km}$ in the Lambert projection (Fig. 1), and we set 30 vertical levels extending from the surface to $50 \mathrm{hPa}$. The physics option follows the one outlined in Lin et al. (2015), including the WRF single-moment 3-class microphysics scheme (Hong et al. 2004), the Rapid Radiative Transfer Model for longwave radiation (Mlawer et al. 1997), the Dudhia shortwave radiation (Dudhia 1989), the unified Noah land surface model (Chen and Dudhia 2001), the revised MM5 Monin-Obukhov surface layer scheme, the Yonsei University (YSU) planetary boundary layer (Hong et al. 2006), and the Kain-Fritsch (new Eta) cumulus scheme (Kain and Fritsch 1990). The initial and lateral boundary conditions for the simulations are from the National Centers for Environmental Prediction (NCEP) final analysis $(\mathrm{FNL})$ with a $0.25^{\circ} \times 0.25^{\circ}$ spatial resolution every 6 hours (NCEP 2015). We initialize the WRF experiments at 1800 UTC every day from 1 August 2015 to 31 July 2017. Each experiment has a lead time of 30 hours, and the simulations of the first 6 hours are for model spinup. The hourly simulations of precipitation and 2-m temperature obtained from the independent forecast runs during the two years are evaluated. Because we observed that the WRF precipitation simulations often start to degrade if the lead time is greater than 2 days, we did not choose to run a 2-yr continuous experiment or experiments with longer lead times (e.g., 3 or 5 days).

\section{c. Evaluation methods}

To evaluate the quality of the aforementioned precipitation products, we use the reference NCEP Stage IV precipitation product (Lin 2011), which has a resolution of $4 \mathrm{~km} \times 4 \mathrm{~km}$ every hour over the continental United States since 2002. Radar-based products have significant uncertainties estimating snowfall (Wen et al. 2016), which raises the question whether the radar-based Stage IV precipitation product is a good reference, especially when the temperature is below the freezing point

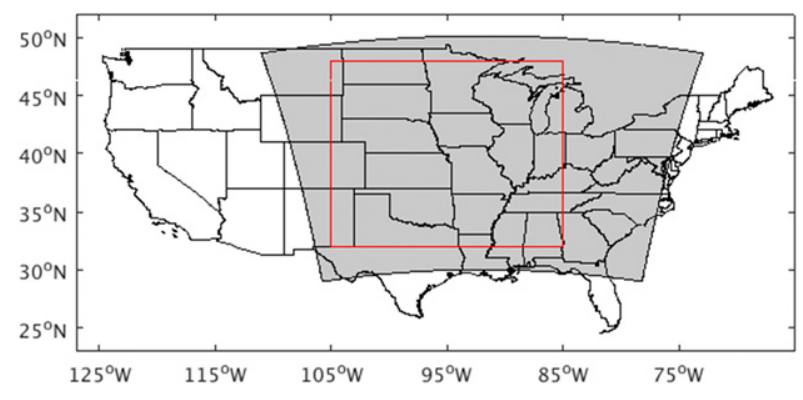

FIG. 1. Domains for WRF simulations (shaded area) and for evaluating the precipitation products (red box).

(i.e., $273 \mathrm{~K}$ ). The Stage IV product incorporates qualitycontrolled gauge measurements, and the central United States, where this study focuses on, has a dense gauge station coverage, which ensures a high quality of the Stage IV product for the central United States (Nelson et al. 2016). Moreover, nine winter weather events over the eastern Rocky Mountains showed that the Stage IV product agrees closely with gauge measurements (Cocks et al. 2016). Therefore, Stage IV is a trustworthy reference in this study.

For brevity, we use ST4, WRF, IMERG_E, and IMERG_F to represent the precipitation products from the NCEP Stage IV dataset, WRF simulations, IMERG early run, and IMERG final run, respectively. We linearly interpolate all the products onto an area of interest (see Fig. 1) with a gridded spatial resolution of $0.1^{\circ}$ and compare all the products within the two years at hourly and daily scales. To quantify the quality of the products, we use the bias, the mean absolute difference (MAD), and the Pearson correlation, defined as

$$
\begin{aligned}
\operatorname{bias} & =\frac{1}{n} \sum_{i=1}^{n}\left(X_{i}^{e}-X_{i}^{r}\right), \\
\operatorname{MAD} & =\frac{1}{n} \sum_{i=1}^{n}\left|X_{i}^{e}-X_{i}^{r}\right|, \quad \text { and } \\
\text { correlation } & =\frac{\operatorname{cov}\left(X^{e}, X^{r}\right)}{\sigma_{X^{e}} \sigma_{X^{r}}},
\end{aligned}
$$

where $X_{i}^{e}$ and $X_{i}^{r}$ are gridded precipitation estimates from IMERG/WRF and the reference NCEP Stage IV dataset, respectively; $\operatorname{cov}\left(X^{e}, X^{r}\right)$ is the covariance of $X^{e}$ and $X^{r} ; \sigma_{X^{e}}$ and $\sigma_{X^{r}}$ are the standard deviations of $X^{e}$ and $X^{r}$, respectively. To demonstrate the hypothesis described in the introduction, we evaluate the precipitation products with and without the information of 2-m temperatures. Specifically, we compute the quality metrics by grouping the precipitation samples according to the 2-m temperature at the corresponding times and locations. 


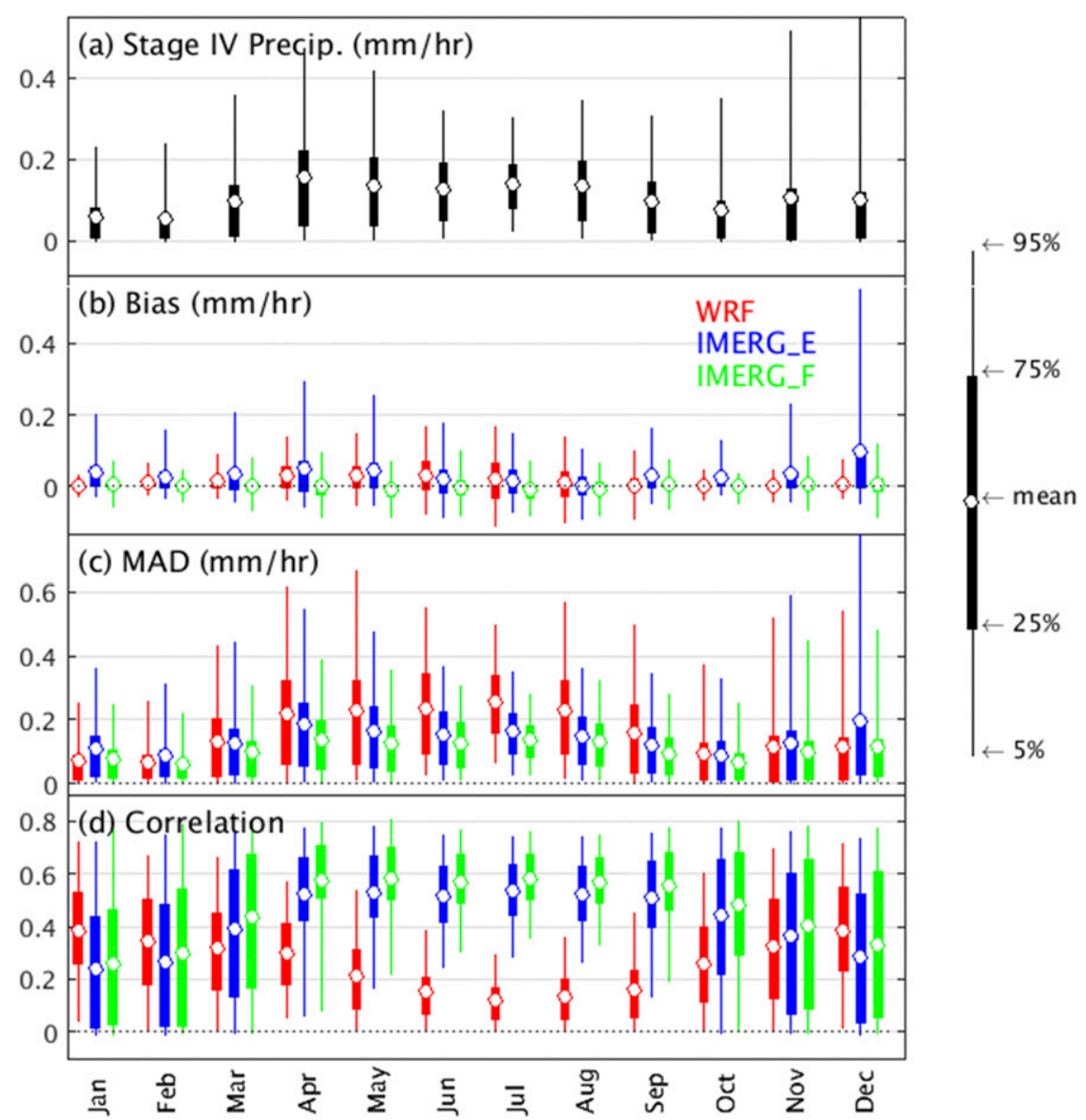

FIG. 2. The percentiles and the mean value of (a) domain-mean hourly NCEP Stage IV precipitation, (b) domain-mean biases, (c) MADs, and (d) spatial correlations in each month. The quality metrics in (b)-(d) are from comparisons of gridded hourly WRF, IMERG earlyrun, and IMERG final-run precipitation products with the reference product every hour.

\section{Results}

\section{a. Evaluation of the precipitation products without considering temperature}

We begin by evaluating the hourly precipitation estimates from the WRF experiments and the IMERG early and final runs without considering 2-m temperatures. For each hour, we compute the domain-mean precipitation from the reference NCEP Stage IV dataset and compute the bias, MAD, and correlation between the gridded hourly precipitation estimates from WRF/IMERG relative to those from the reference. Figure 2 presents various percentiles of the metrics as well as the domain-mean precipitation of the reference in each month. The results show that the WRF product is positively biased in the warm season, the IMERG early-run product is positively biased throughout the year, and the IMERG final-run product is nearly unbiased throughout the year (Fig. 2b). In terms of MAD, the WRF product exhibits the lowest quality in the warm season, while in other seasons the skill of the three products is similar (Fig. 2c). Furthermore, the skill of the various products in representing precipitation is significantly different in different seasons in terms of correlation (Fig. 2d). The two IMERG products exhibit high correlations in the warm season and low correlations in the cold season, while the opposite is true for the WRF product. The overall results are consistent with previous studies (Villarini and Krajewski 2007; Kidd et al. 2012; Maggioni et al. 2016). Nonetheless, we note that the range of the correlations during the winter is much wider than that during the summer, indicating that the quality of the IMERG and WRF products varies significantly in the winter. Since precipitation type during the summer is mostly convective, satellites have the ability to capture the magnitude and the spatial patterns while models have a harder time because of uncertainties introduced by cloud parameterizations (Di et al. 2015; Gao et al. 2017). During the winter, however, different types 
2016 January-February (a) Precip. and T2

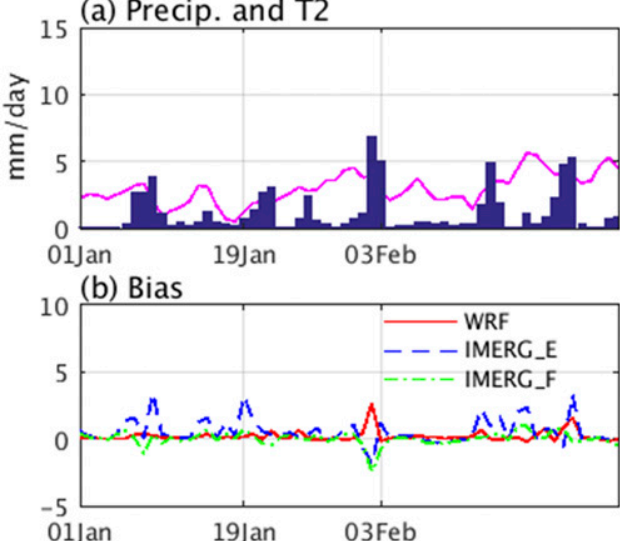

(c) MAD
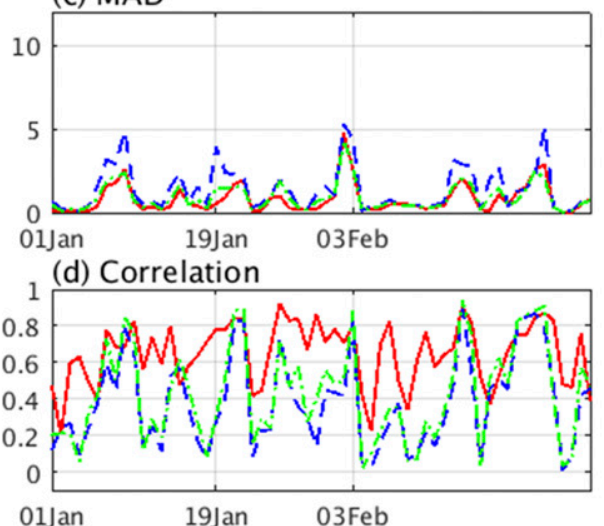

(e) Precip. and T2
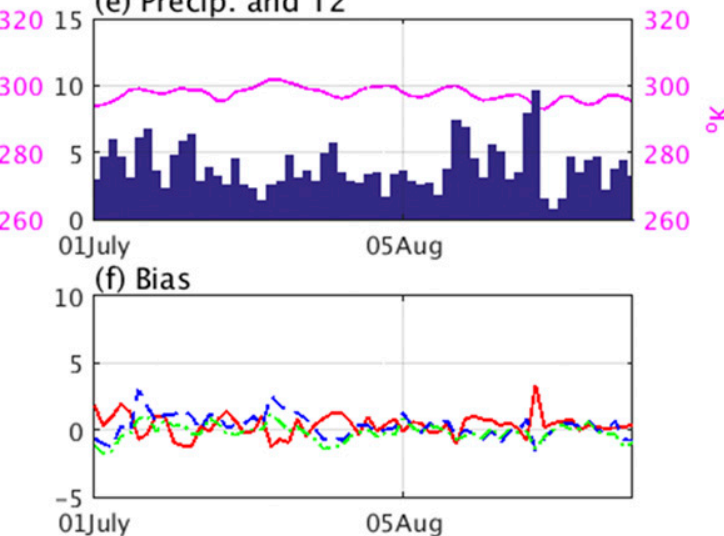

(g) MAD
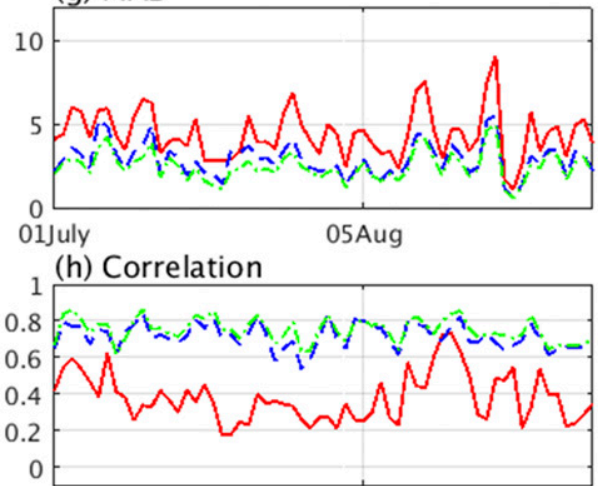

01July

05Aug

FIG. 3. (a),(e) Domain-mean daily-accumulated precipitation from the Stage IV dataset (blue bars) and dailymean 2-m air temperature from the WRF simulations (magenta lines); (b),(f) domain-mean biases; (c),(g) MADs; and (d),(h) spatial correlations. The quality metrics in (b)-(d) and (f)-(h) are from comparisons of gridded daily precipitation products of WRF, IMERG early run, and IMERG final run with the reference Stage IV product.

(e.g., convection and stratiform) and phases (e.g., solid and liquid) of precipitation coexist, which results in difficulties in capturing precipitation features.

We further aggregate the precipitation estimates from hourly to daily and compare their quality on a daily scale. Figure 3 shows the MAD and correlation of gridded daily precipitation estimates as well as the domain-mean bias, reference precipitation, and $2-\mathrm{m}$ temperature in the winter and the summer of 2016. The results at the daily scale (Fig. 3) are consistent with those at the hourly scale (Fig. 2). Figure 4 shows daily precipitation distributions of three frequent situations: 1) low (high) correlation of IMERG (WRF) in the winter (19 January; Figs. 4a-e), 2) high (high) correlation of IMERG (WRF) in the winter (3 February; Figs. 4f-j), and 3) high (low) correlation of IMERG (WRF) in the summer (5 August; Figs. $4 \mathrm{k}-\mathrm{O}$ ). For the summer case (Figs. 4k-O), the WRF model does not accurately capture the location of precipitation, especially around the Great Lakes, where WRF shows significant but incorrect precipitation. In contrast, for the first winter case (Figs. 4a-e), the WRF Model captures the precipitation distribution and magnitude well, while both the IMERG early and final runs do not. For the second winter case (Figs. 4f-j), WRF represents ST4 well and IMERG misses nearly all of the ST4 precipitation in the upper half of the domain. However, in the southeastern corner, IMERG agrees with ST4 very well. We can see, though, that the quality of IMERG appears to be good over relatively warm areas (e.g., those above $280 \mathrm{~K}$ ) even in the winter (Fig. 4f). It seems that the temperature can better inform the quality of IMERG and WRF than seasons or locations.

\section{b. Evaluation of the precipitation products at various temperatures}

We further elucidate the relationship between the quality of the high-resolution precipitation products and air temperature. To this end, we discretize the temperatures into 
January 19

(a) T2 2 (2).04 ( $\left.{ }^{\circ} \mathrm{K}\right)$

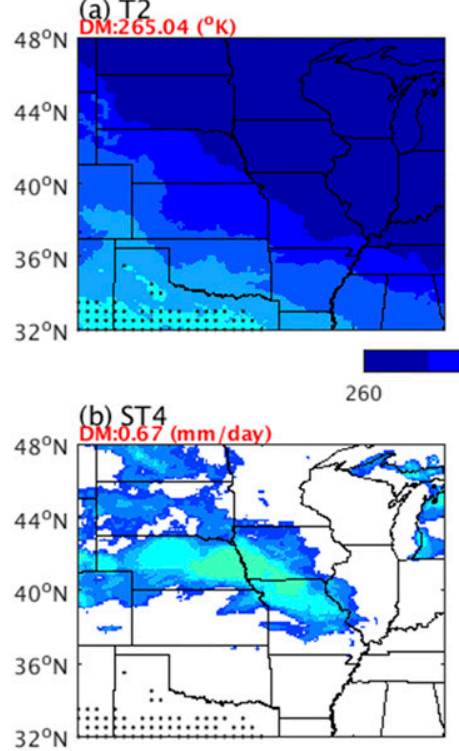

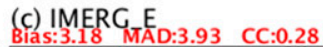

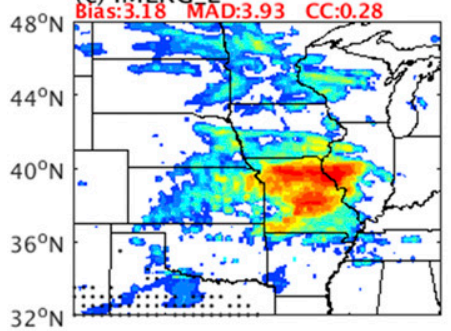

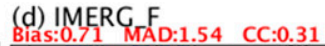

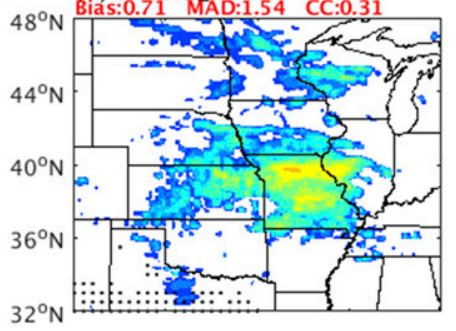

(e) WRE

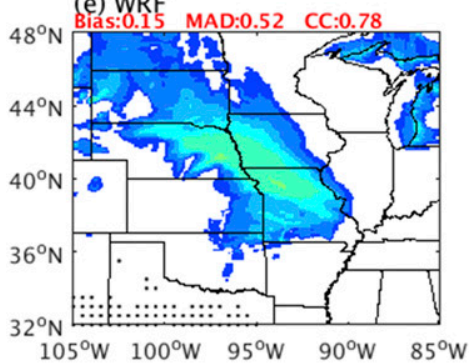

February 3
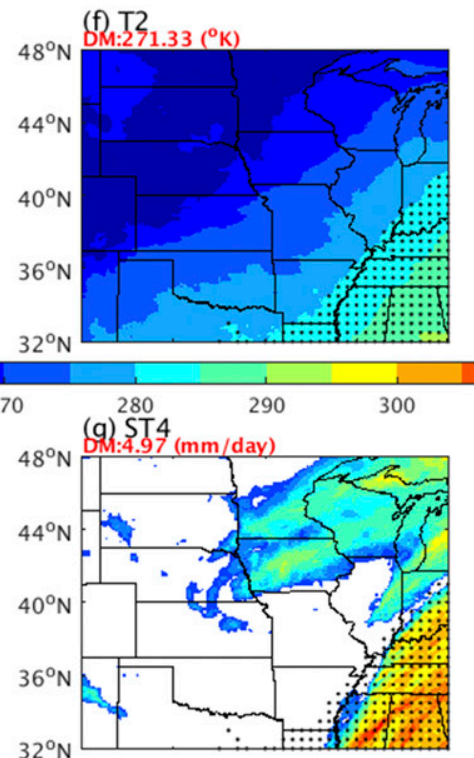

(h) IMERG E

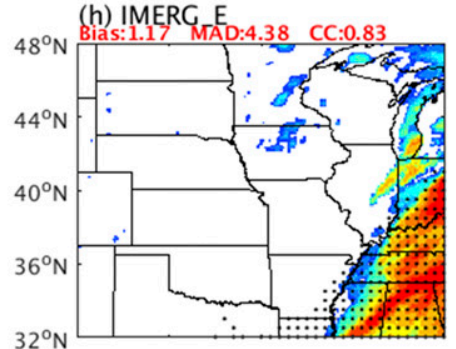

(i) IMERG $F$

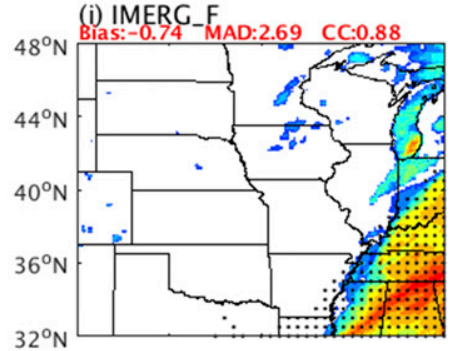

(j) WRF 18 MAD:2.53 $\quad$ CC:0.80

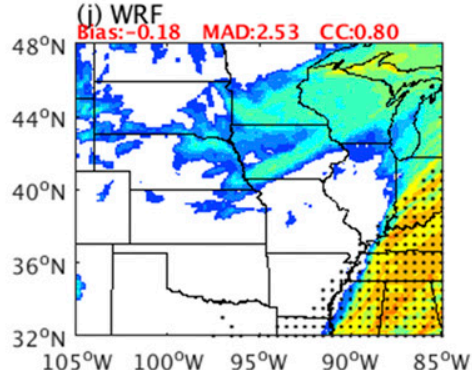

August 5
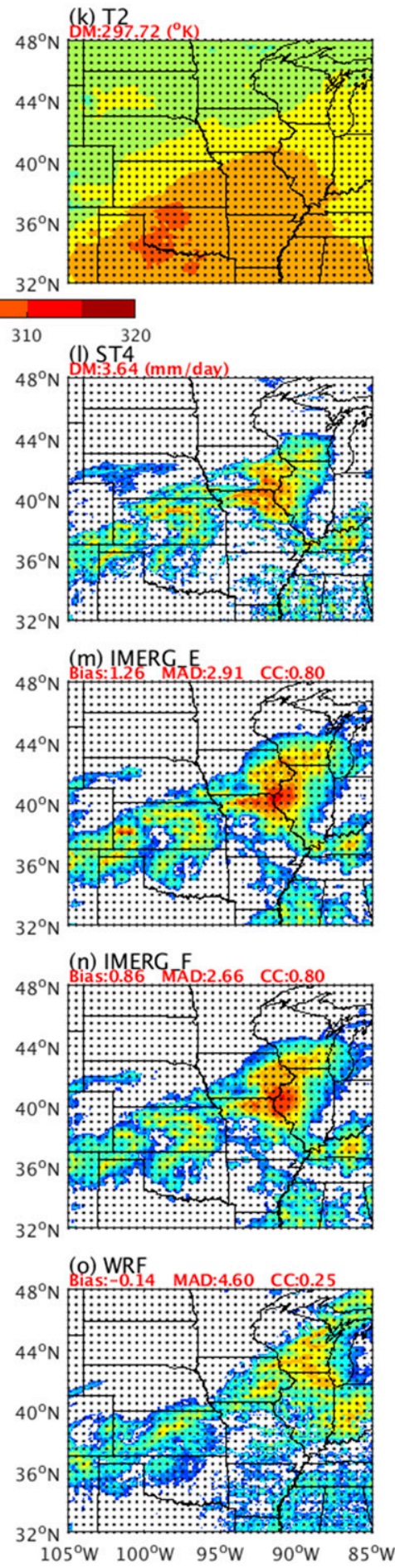

$\begin{array}{llllllllllllll}0 & 0.5 & 1 & 2 & 3 & 5 & 10 & 15 & 20 & 30 & 50 & 70 & 100 & 300\end{array}$

FIG. 4. The spatial distribution of (a),(f),(k) daily-mean air temperature simulations and (b)-(e), (g)-(j), (i)-(o) daily precipitation accumulations on three selected dates in 2016. DM stands for domain mean. The biases, MADs, and correlations (CC) are reported by comparing the WRF/IMERG daily precipitation with the reference (ST4). Regions above $280 \mathrm{~K}$ are shaded with dots. 
(a) Stage IV Precip. ( $\mathrm{mm} / \mathrm{hr})$
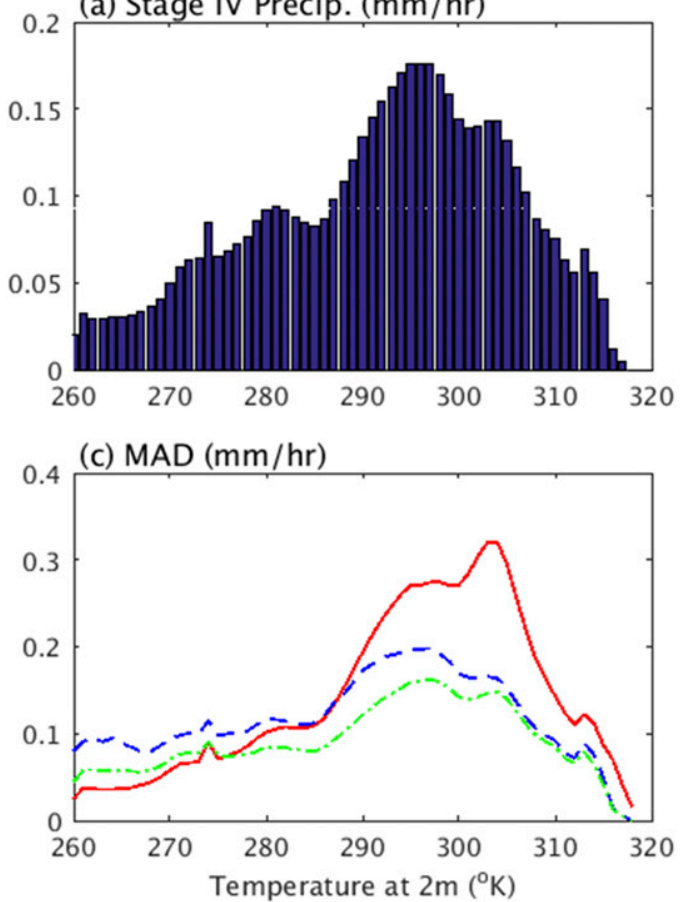

(b) Bias $(\mathrm{mm} / \mathrm{hr})$

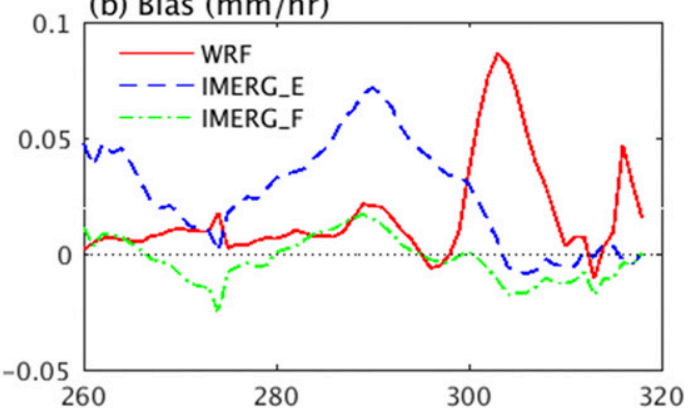

(d) Correlation

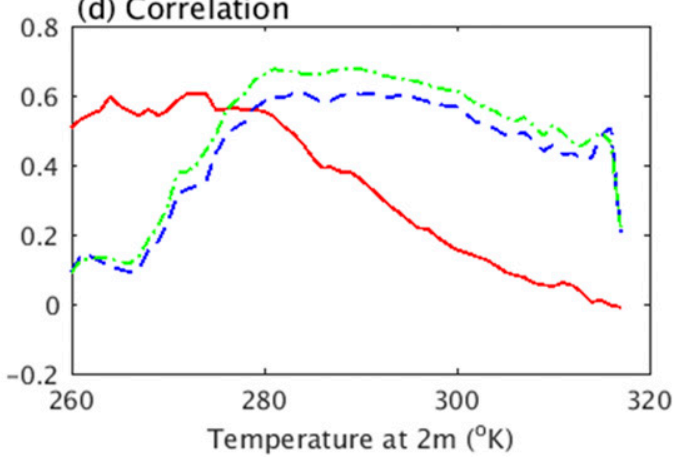

FIG. 5. (a) The average Stage IV precipitation and (b) the biases, (c) MADs, and (d) correlations at various temperatures from comparisons of hourly $0.1^{\circ} \times 0.1^{\circ}$ precipitation estimates from WRF and IMERG early and final runs with the Stage IV product. The temperature varies from 260 to $320 \mathrm{~K}$ at $1-\mathrm{K}$ intervals. The shown metrics have a minimum precipitation sample size of 500 in each $1-\mathrm{K}$ temperature bin.

$1^{\circ}$ bins varying from 260 to $318 \mathrm{~K}$ and group all the hourly gridded precipitation samples into the bins based on the temperature of the corresponding time and location. Figure 5 shows the average precipitation from the reference Stage IV product and the quality metrics of WRF and IMERG products at various temperatures. Precipitation occurs commonly within a temperature range of 290-310 K (Fig. 5a). Figure 5b shows that IMERG_F is nearly unbiased, while IMERG_E tends to overestimate precipitation for temperatures below $300 \mathrm{~K}$, and WRF does so when the temperature is above $300 \mathrm{~K}$. The bias of WRF is reflected in the MAD, which is significantly higher than the IMERG MAD when the temperature is above $300 \mathrm{~K}$ (Fig. 5c). When the temperature is between 280 and $300 \mathrm{~K}$, even though WRF has a smaller bias, the MAD of WRF is larger than that of IMERG, suggesting that random errors occur more often in WRF than IMERG in this temperature range. In terms of correlation, the quality of warm and cold precipitation for each product exhibits sharp contrasts (Fig. 5d). When the temperature is below $280 \mathrm{~K}$, the correlation of WRF remains relatively high at an average of around 0.6 , but above $280 \mathrm{~K}$, the correlation decreases rapidly to 0 as the temperature increases. In contrast, the two
IMERG products exhibit a low but increasing correlation when the temperature is below $280 \mathrm{~K}$, and the correlation remains relatively constant at an average of around 0.6 when the temperature exceeds $280 \mathrm{~K}$. The results demonstrate further that temperature can effectively inform the difference in quality between the WRF and IMERG precipitation products.

To better understand the relationship between temperature and precipitation, we analyze further the seasonal variability of the quality of the IMERG and WRF products at various temperatures. For brevity, we consider only the correlation metric. As the differences in correlations between the IMERG early and final runs are insignificant, we present only the results of WRF and IMERG_F. For each month, we first group hourly gridded precipitation estimates based on the air temperature in $1^{\circ}$ bins, and then in each temperature bin, we compute the correlation metric of WRF/IMERG and the reference NCEP Stage IV dataset (Fig. 6). Similar to Fig. 5d, the quality of WRF/IMERG differs above and below the temperature around $280 \mathrm{~K}$ (Fig. 6c). More importantly, it appears that air temperature is a more effective indicator of the quality of WRF/IMERG precipitation than seasonality. Figure $6 \mathrm{c}$ shows that even in the winter, the IMERG product outperforms the WRF product over warm surfaces, while 


\section{(a) IMERG_F}

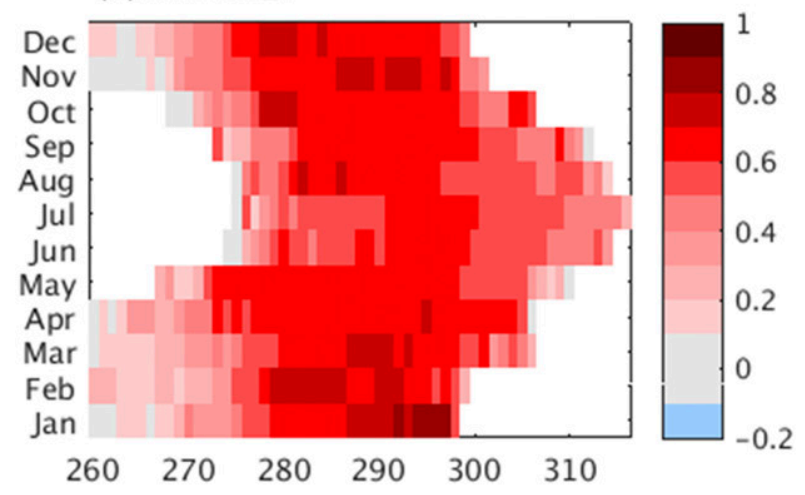

(b) WRF

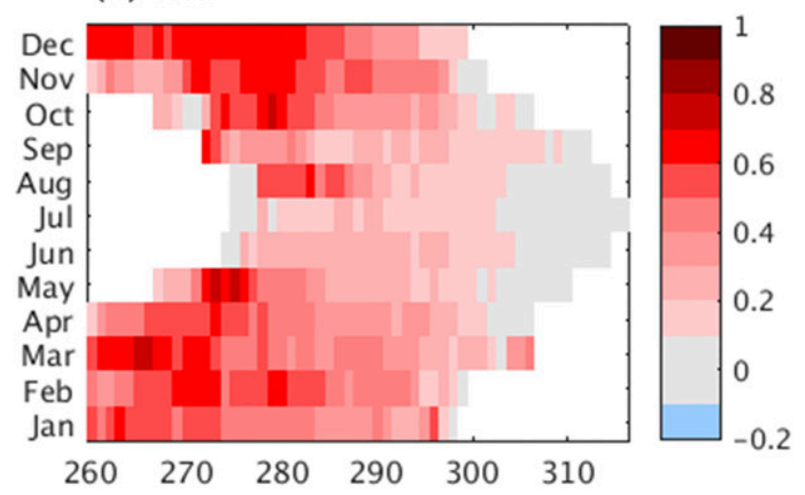

(c) IMERG_F - WRF

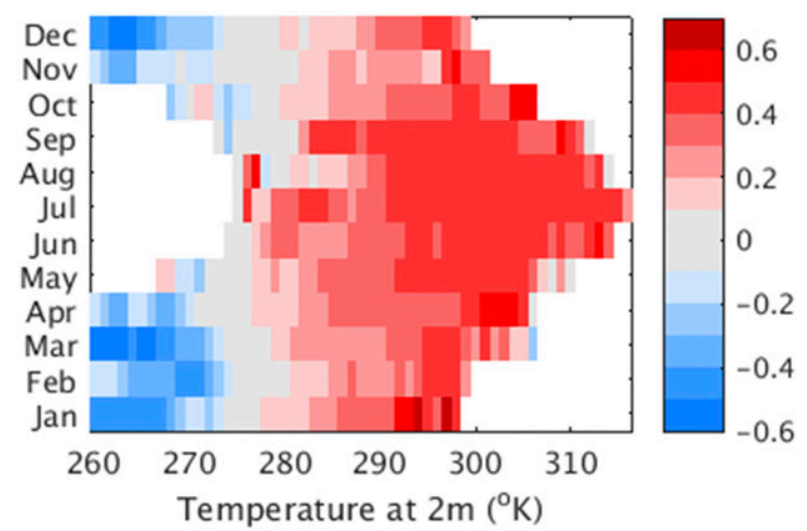

FIG. 6. The correlations of (b) WRF and (a) IMERG final-run hourly $0.1^{\circ} \times 0.1^{\circ}$ precipitation estimates relative to the NCEP Stage IV data at various $2-m$ air temperatures in each month. The reported correlations contain a minimum precipitation sample size of 500 in each $1^{\circ}$ temperature bin. (c) The difference between (a) and (b).

this phenomenon cannot be observed in Fig. 2d. The variation of correlation over various $2-\mathrm{m}$ temperatures during the winter shown in Fig. 6 explains the spread of correlation seen in Figs. 2d and 3d. In contrast, in the summer, as 2-m temperatures are mostly greater than $280 \mathrm{~K}$, the correlation of IMERG is often larger than that of WRF, which agrees well with Figs. $2 \mathrm{~d}$ and $3 \mathrm{~h}$.
We also analyze the spatial variability of the quality of the IMERG and WRF precipitation products at various temperatures. For each $0.1^{\circ} \times 0.1^{\circ}$ spatial grid, we group hourly precipitation samples into four temperature ranges (i.e., less than $270 \mathrm{~K}$, between 270 and $280 \mathrm{~K}$, between 280 and $290 \mathrm{~K}$, and greater than $290 \mathrm{~K}$ ). For each spatial grid and each temperature range, we compute the correlation between IMERG/WRF precipitation and the reference precipitation (Fig. 7). The results agree with Figs. 5 and 6 and further demonstrate that the relationship between 2-m air temperature and the quality of WRF/IMERG precipitation products does not depend on location. Furthermore, with a temperature between 270 and $280 \mathrm{~K}$, the correlation values over the southern domain are higher than those over the northern domain (Figs. $7 \mathrm{~b}$ and $7 \mathrm{f}$ ), which could be attributed to smaller chances of solid and mixed-phase precipitation over the southern domain.

\section{Discussion}

The WRF Model can be configured differently, and the configuration in this study is only one example. To verify the robustness of our results, we run two more WRF simulations with different configurations. For the first simulation, we use a different physics option favoring convection over the continental United States. To distinguish this physics option from that in section $2 b$, the two options are referred to as the convection option and the original option, respectively. The convection option is provided by NCAR (http://www2.mmm.ucar.edu/wrf/ users/wrfv3.9/conus_suite.html), and it includes the Thompson microphysics scheme (Thompson et al. 2008), the Rapid Radiative Transfer Model-Global (RRTMG) for shortwave and longwave radiation (Iacono et al. 2008), the unified Noah land surface model (Chen and Dudhia 2001), the Eta similarity scheme for surface layer (Monin and Obukhov 1954; Janjić 1994, 1996, 2002), the Mellor-Yamada-Janjić planetary boundary layer (Janjić 1994), and the Tiedtke cumulus scheme (Tiedtke 1989; Zhang et al. 2011). The statistics of precipitation estimates from the convection option are shown in Figs. 8a-d. The precipitation estimates of the convection option (red lines in Figs. 8b-d) show little difference from those of the original option (red lines in Figs. 5b-d) when the temperature is low (e.g., below $290 \mathrm{~K}$ ). When the temperature is high (e.g., above $290 \mathrm{~K}$ ), the magnitude of precipitation is different with different physics options, but precipitation is not well simulated whatever physics option is used because convective systems cannot be resolved on the configured spatial scale.

For the second simulation, we use a $4 \mathrm{~km} \times 4 \mathrm{~km}$ high-resolution domain nested in a $12 \mathrm{~km} \times 12 \mathrm{~km}$ 
IMERG_F

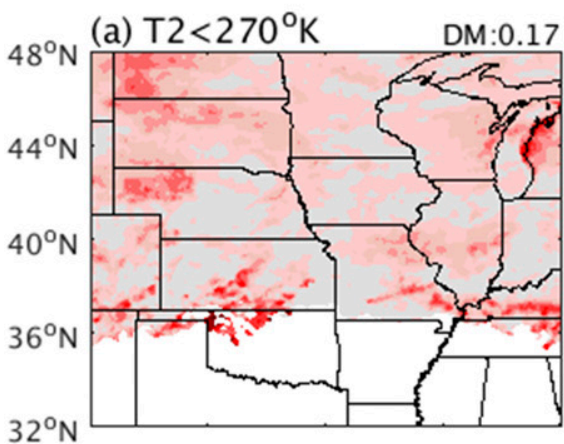

(b) $270<\mathrm{T} 2<280^{\circ} \mathrm{K} \quad \mathrm{DM}: 0.58$

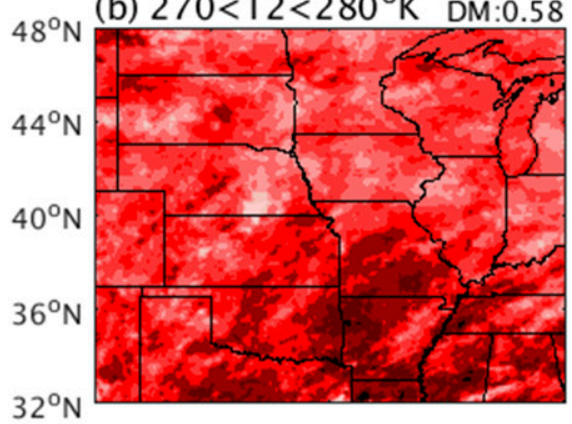

(c) $280<\mathrm{T} 2<290^{\circ} \mathrm{K} \quad \mathrm{DM}: 0.67$
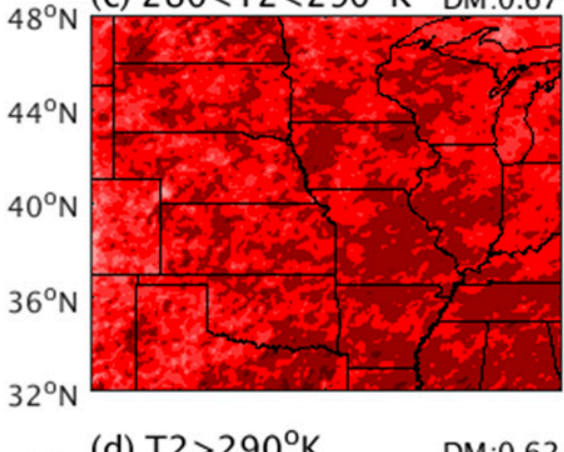

(e) $\mathrm{T} 2<270^{\circ} \mathrm{K}$

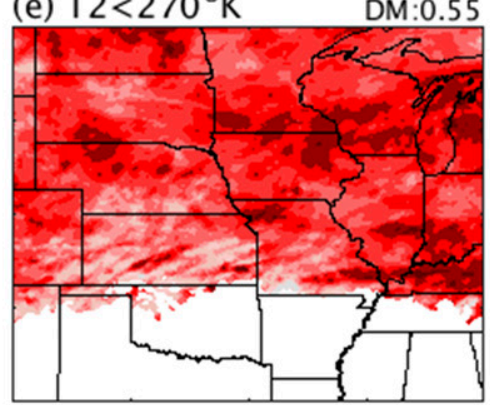

(f) $270<\mathrm{T} 2<280^{\circ} \mathrm{K} \quad \mathrm{DM}: 0.57$

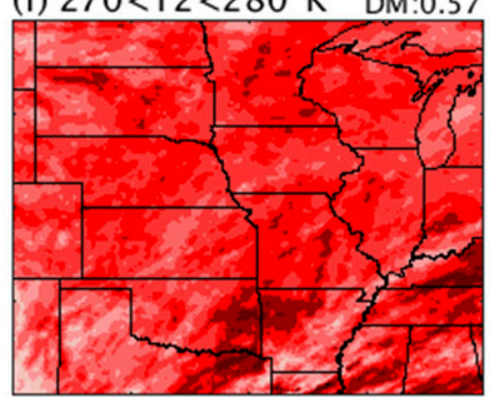

(g) $280<\mathrm{T} 2<290^{\circ} \mathrm{K}$ DM:0.39

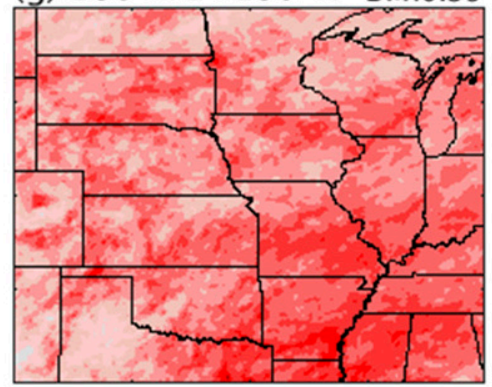

(h) $\mathrm{T} 2>290^{\circ} \mathrm{K}$

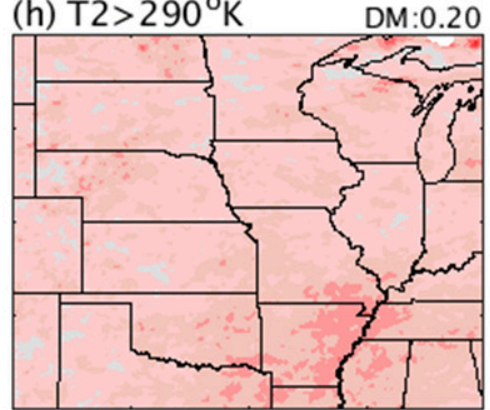

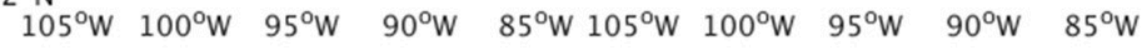

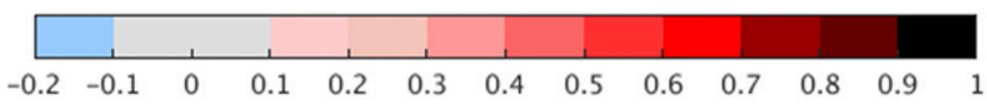

FIG. 7. The spatial distribution of the correlations of (a)-(d) IMERG final-run and (e)-(h) WRF estimates relative to the NCEP Stage IV data within various 2-m temperature ranges (i.e., below $270 \mathrm{~K}$, between 270 and $280 \mathrm{~K}$, between 280 and $290 \mathrm{~K}$, and above $290 \mathrm{~K}$ ). The domain-mean (DM) correlations are reported at the upper-right corner of each subplot. The results on a grid cell with a sample size larger than 500 are shown. 
(a) Stage IV Precip. $(\mathrm{mm} / \mathrm{hr})$

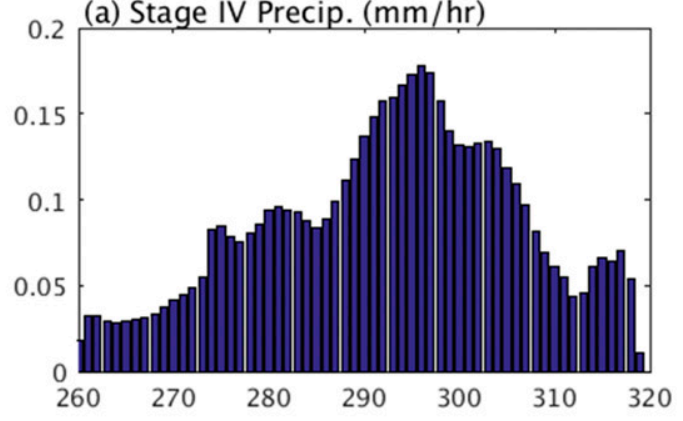

(b) Bias $(\mathrm{mm} / \mathrm{hr})$
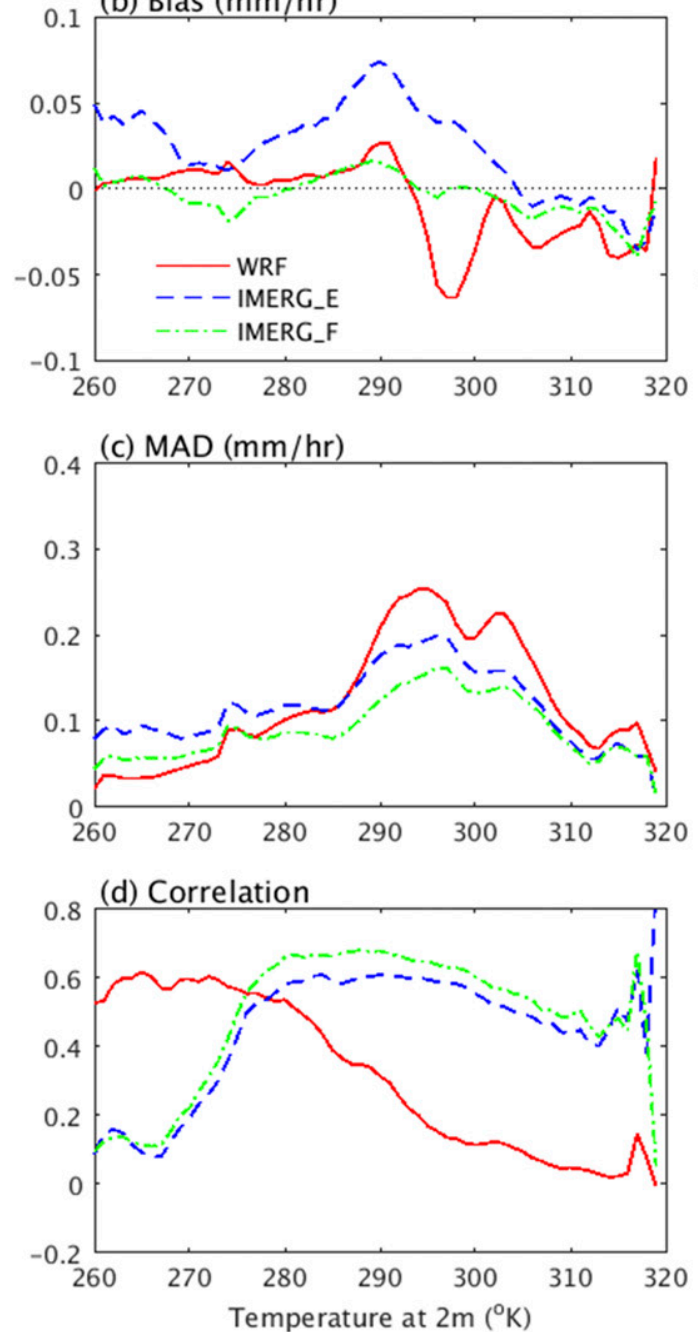

(e) Stage IV Precip. $(\mathrm{mm} / \mathrm{hr})$
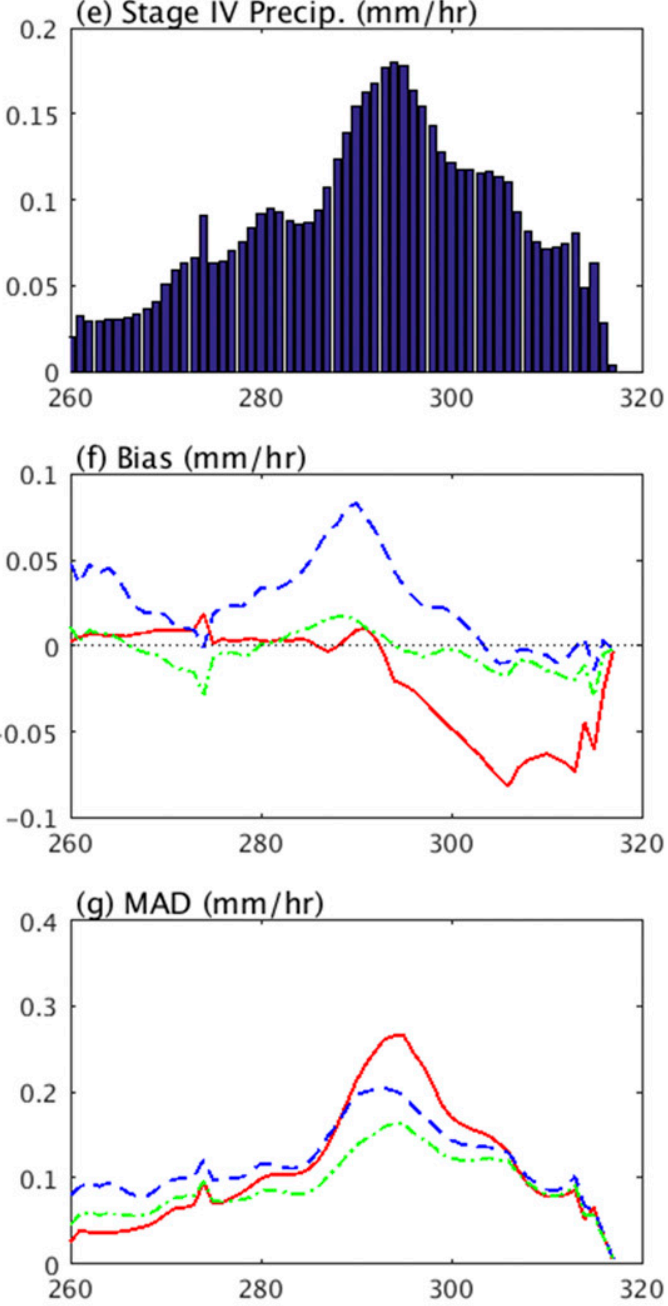

(h) Correlation

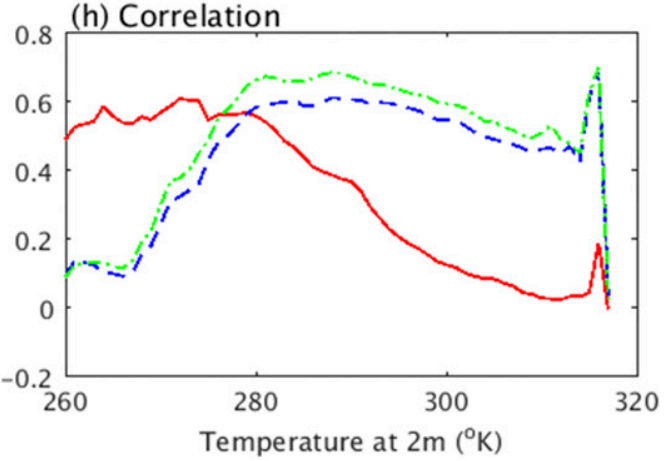

FIG. 8. (a)-(d) As in Figs. 5a-d, but the WRF simulations are from a convection-favoring physics option. (e)-(h) As in Figs. 5a-d, but the WRF simulations are from a high-resolution configuration.

domain to avoid cumulus parameterizations. The physics option is the same as the original option except that the high-resolution domain is configured without cumulus schemes (hereafter high-resolution option). The estimates at $4 \mathrm{~km}$ are then interpolated to $0.1^{\circ}$ for analysis. Figures $8 \mathrm{e}-\mathrm{h}$ show the statistics of precipitation estimates from the high-resolution option, along with those from IMERG. Similar to the estimates from the convection option (red lines in Figs. 8b-d), those from the high-resolution option underestimate precipitation and do not capture the magnitude and spatial distribution well over warm surfaces (red lines in Figs. 8f-h). 
(a) Stage IV Precip. (mm/day)

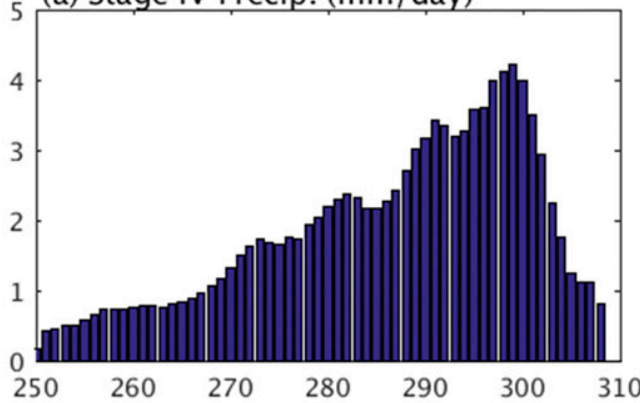

(b) Bias (mm/day)

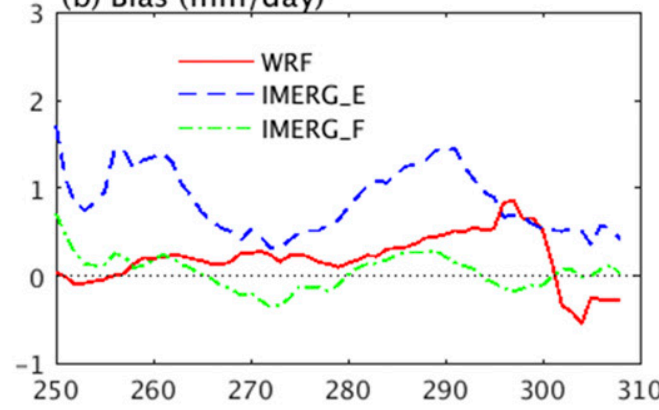

(c) MAD (mm/day)
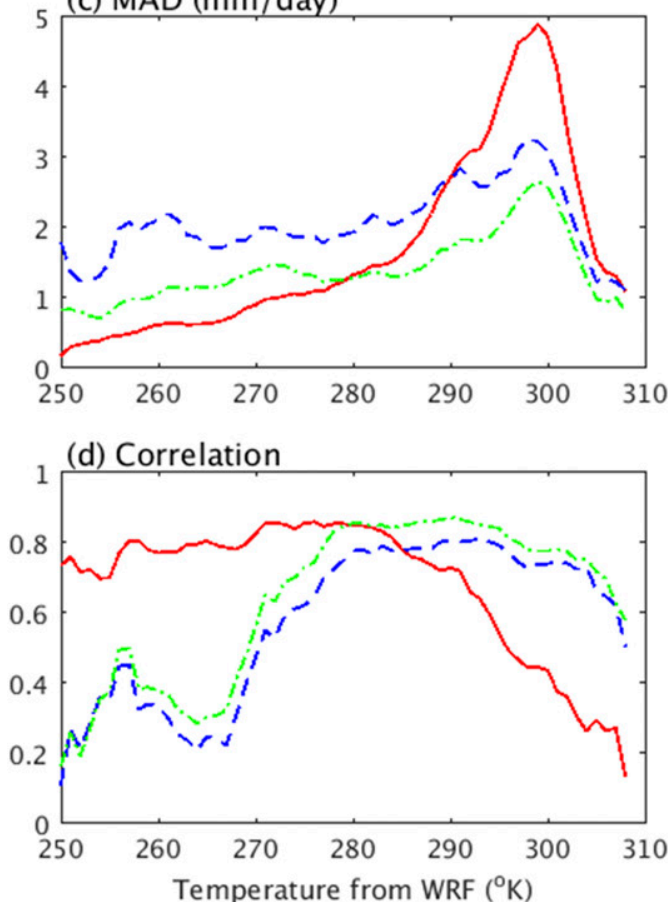

(e) Stage IV Precip. (mm/day)

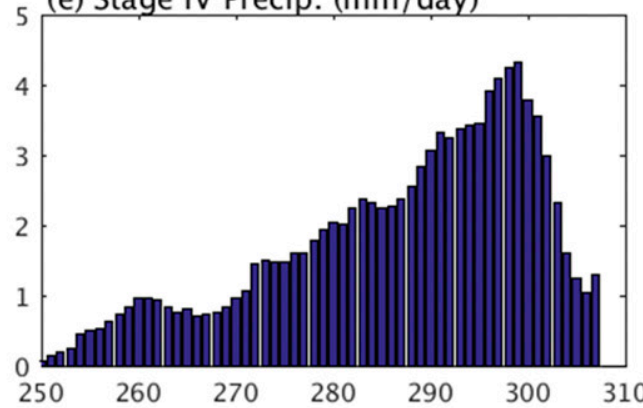

(f) Bias (mm/day)

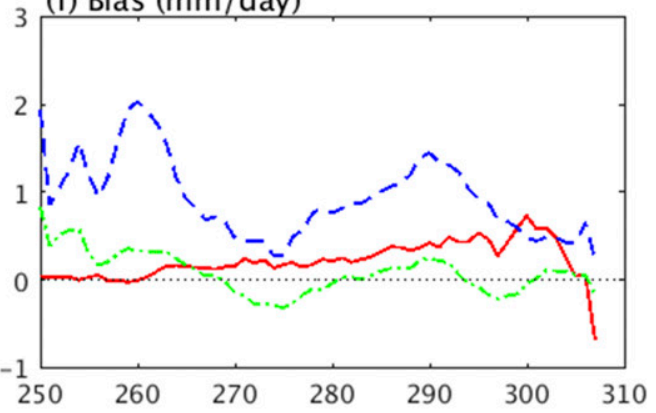

(g) MAD (mm/day)

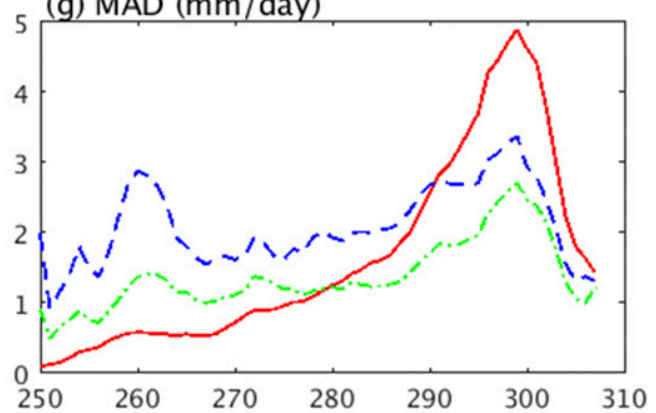

(h) Correlation

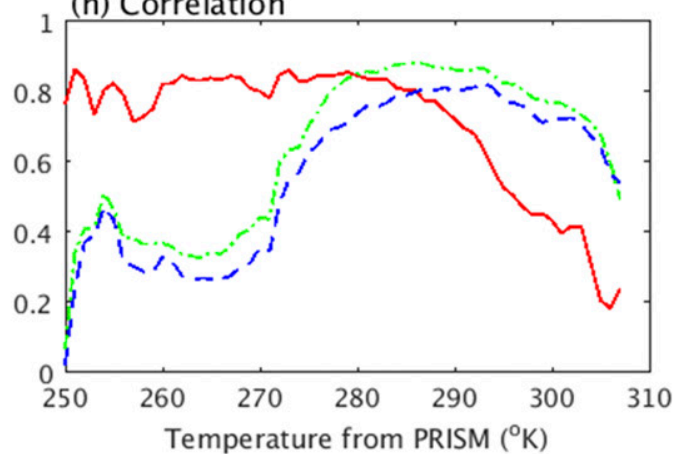

FIG. 9. (a)-(d) As in Figs. 5a-d, but the statistics are calculated based on daily precipitation instead of hourly precipitation. (e)-(h) As in (a)-(d), but the temperature product is from PRISM instead of WRF.

Overall, the two simulations show that the quality of WRF precipitation estimates does not change much with physics options or grid resolution, indicating that physics parameterization is not the key factor that challenges the ability of models simulating precipitation, and thus our results are robust in terms of WRF physics parameterization.

One may argue that the temperature product and the WRF precipitation product are dependent since they are from the same WRF simulations, and thus the 
results based on the WRF temperature may be biased. To address the concern, we repeat the analysis using an independent temperature product, the ParameterElevation Regression on Independent Slopes Model (PRISM; PRISM Climate Group 2018). The PRISM temperature has a $\sim 4-\mathrm{km}$ Gaussian grid spatial resolution and daily temporal resolution. To compare the results based on WRF temperature and those based on PRISM temperature, we aggregate (average) hourly precipitation (temperature) into daily accumulation (mean), and interpolate all the products into the same $0.1^{\circ} \times 0.1^{\circ}$ spatial grids. The statistics of daily products based on WRF temperature and PRISM temperature are shown in Figs. 9a-d and Figs. 9e-h, respectively. The WRF and IMERG precipitation products at the daily scale (Figs. 9a-d) agree with those at the hourly scale (Figs. 5a-d): the WRF product captures the precipitation pattern and magnitude well when temperature is below $280 \mathrm{~K}$ but fails to do so when temperature is above $280 \mathrm{~K}$. The IMERG products have the opposite behavior. Moreover, the quality of these products based on the WRF temperature (Figs. 9a-d) show little difference from that based on the independent PRISM temperature (Figs. 9e-h), indicating that the results based on the WRF temperature are unbiased.

\section{Conclusions}

This study evaluated model- and satellite-based hourly precipitation products (i.e., WRF simulations and version 5 IMERG early- and final-run retrievals, respectively) at a gridded spatial resolution of $0.1^{\circ}$ over the central United States during August 2015-July 2017. It is well known that satellite-based products exhibit higher accuracy in the summer while modelbased products do so in the winter. However, this study found that the spatial correlations of these precipitation products vary extensively in the winter, indicating that seasonality cannot fully characterize the behavior of the quality of the precipitation products. We introduced 2-m air temperature as auxiliary information and demonstrated that we can distinguish the quality of model- and satellite-based precipitation products more effectively using 2-m air temperature as an index. Specifically, when the temperature is below $270 \mathrm{~K}$, the WRF product is more accurate than the IMERG products; when the temperature is above $280 \mathrm{~K}$, the situation is reversed; and when the temperature falls between 270 and $280 \mathrm{~K}$, the WRF and IMERG products are comparable. We further demonstrated that this phenomenon is true over various seasons and locations.
The observed relationship between temperature and the quality of precipitation products can be rationalized. On one hand, temperature is associated with precipitation phases-snowfall usually occurs with cold air temperatures and rainfall with warm temperatures. For satellite-based products, rainfall retrievals are rather mature but snowfall retrievals are a challenge, partly because the radiative properties of snowfall particles are much more complex than water droplets and snowfall has weak signals at low microwave frequencies. In the GPM era, although high-frequency channels are designed to estimate snowfall, the retrieval of snowfall is still at its early stage of development. Temperature is also associated with precipitation types-large-scale precipitation dominates at cold air temperatures and convective precipitation at warm temperatures. Convective precipitation is properly estimated from satellites because of strong signal contrasts between cloud tops and surroundings, but it is not well simulated from models because convective systems occur on finer spatial scales than those models can resolve. As satellitebased precipitation products share similar issues in retrieving snowfall and model-based products in simulating convective systems, the relationship between the quality of precipitation products and temperature revealed based on IMERG and WRF products could be true for other satellite- and model-based precipitation products as well.

As precipitation products show distinct performance over different terrains (Chen et al. 2015; Maggioni et al. 2016), the results obtained from this study may be limited to areas with terrain similar to that of the central United States. It is also noted that we analyzed only two years of data because of the limited length of the NCEP FNL dataset that drives the WRF simulations. We found that the results from two years of data are similar to those from one year (figures not shown), and thus it is expected that the length of data would not change the results much. Nevertheless, studying the relationship between temperature and the quality of precipitation products over other regions and with a longer period would be worthy of future investigations.

Acknowledgments. This research is sponsored by the NASA Precipitation Measurement Mission (PMM) science program through Grant NNX16AE36G. The WRF Model was obtained from the National Center for Atmospheric Research (NCAR). The FNL data were provided by the Computational and Information Systems Laboratory at NCAR. The NCEP Stage IV precipitation data were provided by the Earth Observing Laboratory at NCAR. We thank three anonymous reviewers for their valuable comments and suggestions. 


\section{REFERENCES}

Adler, R. F., C. Kidd, G. Petty, M. Morissey, and H. M. Goodman, 2001: Intercomparison of global precipitation products: The third Precipitation Intercomparison Project (PIP-3). Bull. Amer. Meteor. Soc., 82, 1377-1396, https://doi.org/10.1175/ 1520-0477(2001)082<1377:IOGPPT>2.3.CO;2.

Baxter, M. A., G. M. Lackmann, K. M. Mahoney, T. E. Workoff, and T. M. Hamill, 2014: Verification of quantitative precipitation reforecasts over the southeastern United States. Wea. Forecasting, 29, 1199-1207, https://doi.org/10.1175/WAF-D-14-00055.1.

Beck, H. E., A. I. J. M. van Dijk, V. Levizzani, J. Schellekens, D. G. Miralles, B. Martens, and A. de Roo, 2017: MSWEP: 3-hourly $0.25^{\circ}$ global gridded precipitation (1979-2015) by merging gauge, satellite, and reanalysis data. Hydrol. Earth Syst. Sci., 21, 589-615, https://doi.org/10.5194/hess-21-589-2017.

Behrangi, A., K. Andreadis, J. B. Fisher, F. J. Turk, S. Granger, T. Painter, and N. Das, 2014: Satellite-based precipitation estimation and its application for streamflow prediction over mountainous western U.S. basins. J. Appl. Meteor. Climatol. 53, 2823-2842, https://doi.org/10.1175/JAMC-D-14-0056.1. , H. Nguyen, B. Lambrigtsen, M. Schreier, and V. Dang, 2015: Investigating the role of multi-spectral and near surface temperature and humidity data to improve precipitation detection at high latitudes. Atmos. Res., 163, 2-12, https://doi.org/ 10.1016/j.atmosres.2014.10.019.

Chen, F., and J. Dudhia, 2001: Coupling an advanced land surfacehydrology model with the Penn State-NCAR MM5 modeling system. Part I: Model implementation and sensitivity. Mon. Wea. Rev., 129, 569-585, https://doi.org/10.1175/1520-0493(2001) $129<0569$ :CAALSH $>2.0 . \mathrm{CO} ; 2$.

Chen, S., and Coauthors, 2015: Intercomparison of precipitation estimates from WSR-88D radar and TRMM measurement over continental United States. IEEE Trans. Geosci. Remote Sens. 53, 4444-4456, https://doi.org/10.1109/TGRS.2015.2399307.

Cocks, S. B., S. M. Martinaitis, B. Kaney, J. Zhang, and K. Howard, 2016: MRMS QPE performance during the 2013/14 cool season. J. Hydrometeor., 17, 791-810, https://doi.org/10.1175/ JHM-D-15-0095.1.

Di, Z., and Coauthors, 2015: Assessing WRF Model parameter sensitivity: A case study with 5 day summer precipitation forecasting in the greater Beijing Area. Geophys. Res. Lett., 42, 579-587, https://doi.org/10.1002/2014GL061623.

Dudhia, J., 1989: Numerical study of convection observed during the winter monsoon experiment using a mesoscale twodimensional model. J. Atmos. Sci., 46, 3077-3107, https://doi. org/10.1175/1520-0469(1989)046<3077:NSOCOD>2.0.CO;2.

Ebert, E. E., U. Damrath, W. Wergen, and M. E. Baldwin, 2003: The WGNE assessment of short-term quantitative precipitation forecasts. Bull. Amer. Meteor. Soc., 84, 481-492, https://doi.org/10.1175/BAMS-84-4-481.

_ J. E. Janowiak, and C. Kidd, 2007: Comparison of near-realtime precipitation estimates from satellite observations and numerical models. Bull. Amer. Meteor. Soc., 88, 47-64, https:// doi.org/10.1175/BAMS-88-1-47.

Gao, Y., L. R. Leung, C. Zhao, and S. Hagos, 2017: Sensitivity of U.S. summer precipitation to model resolution and convective parameterizations across gray zone resolutions. J. Geophys. Res. Atmos., 122, 2714-2733, https://doi.org/10.1002/2016JD025896.

Gottschalck, J., J. Meng, M. Rodell, and P. Houser, 2005: Analysis of multiple precipitation products and preliminary assessment of their impact on global land data assimilation system land surface states. J. Hydrometeor., 6, 573-598, https://doi.org/10.1175/JHM437.1.
Hong, S.-Y., J. Dudhia, and S.-H. Chen, 2004: A revised approach to ice microphysical processes for the bulk parameterization of clouds and precipitation. Mon. Wea. Rev., 132, 103-120, https:// doi.org/10.1175/1520-0493(2004)132<0103:ARATIM>2.0.CO;2. , Y. Noh, and J. Dudhia, 2006: A new vertical diffusion package with an explicit treatment of entrainment processes. Mon. Wea. Rev., 134, 2318-2341, https://doi.org/10.1175/MWR3199.1.

Hou, A. Y., and Coauthors, 2014: The Global Precipitation Measurement mission. Bull. Amer. Meteor. Soc., 95, 701-722, https:// doi.org/10.1175/BAMS-D-13-00164.1.

Huffman, G. J., D. T. Bolvin, D. Braithwaite, K. Hsu, R. Joyce, C. Kidd, E. J. Nelkin, and P. Xie, 2015: NASA Global Precipitation Measurement Integrated Multi-Satellite Retrievals for GPM (IMERG). Algorithm Theoretical Basis Doc., version 4.5, 30 pp., http://pmm.nasa.gov/sites/default/files/document_files/ IMERG_ATBD_V4.5.pdf.

Iacono, M. J., J. S. Delamere, E. J. Mlawer, M. W. Shephard, S. A. Clough, and W. D. Collins, 2008: Radiative forcing by long-lived greenhouse gases: Calculations with the AER radiative transfer models. J. Geophys. Res., 113, D13103, https:// doi.org/10.1029/2008JD009944.

Janjić, Z. I., 1994: The step-mountain Eta coordinate model: Further developments of the convection, viscous sublayer, and turbulence closure schemes. Mon. Wea. Rev., 122, 927-945, https://doi.org/ 10.1175/1520-0493(1994)122<0927:TSMECM >2.0.CO;2.

— 1996: The surface layer in the NCEP Eta Model. Preprints, 11th Conf. on Numerical Weather Prediction, Norfolk, VA, Amer. Meteor. Soc., 354-355.

— 2002: Nonsingular implementation of the Mellor-Yamada level 2.5 scheme in the NCEP Meso model. NCEP Office Note 437, 61 pp., http://www.emc.ncep.noaa.gov/officenotes/newernotes/on437.pdf.

Joyce, R. J., J. E. Janowiak, P. A. Arkin, and P. Xie, 2004: CMORPH: A method that produces global precipitation estimates from passive microwave and infrared data at high spatial and temporal resolution. J. Hydrometeor., 5, 487-503, https://doi.org/10.1175/ 1525-7541(2004)005<0487:CAMTPG >2.0.CO;2.

Junker, N. W., J. E. Hoke, B. E. Sullivan, K. F. Brill, and F. J. Hughes, 1992: Seasonal and geographic variations in quantitative precipitation prediction by NMC's nested-grid model and mediumrange forecast model. Wea. Forecasting, 7, 410-429, https:// doi.org/10.1175/1520-0434(1992)007<0410:SAGVIQ>2.0.CO;2.

Kain, J. S., and J. M. Fritsch, 1990: A one-dimensional entraining/ detraining plume model and its application in convective parameterization. J. Atmos. Sci., 47, 2784-2802, https://doi.org/ 10.1175/1520-0469(1990)047<2784:AODEPM > 2.0.CO;2.

Khan, S., V. Maggioni, and L. Porcacchia, 2016: Uncertainties associated with the IMERG multi-satellite precipitation product. 2016 IEEE Int. Geoscience and Remote Sensing Symp., Beijing, China, IEEE, 2127-2130, https://doi.org/10.1109/ IGARSS.2016.7729549.

Kidd, C., P. Bauer, J. Turk, G. J. Huffman, R. Joyce, K.-L. Hsu, and D. Braithwaite, 2012: Intercomparison of high-resolution precipitation products over northwest Europe. J. Hydrometeor., 13, 67-83, https://doi.org/10.1175/JHM-D-11-042.1.

Lin, L.-F., A. M. Ebtehaj, R. L. Bras, A. N. Flores, and J. Wang, 2015: Dynamical precipitation downscaling for hydrologic applications using WRF 4D-Var data assimilation: Implications for GPM era. J. Hydrometeor., 16, 811-829, https:// doi.org/10.1175/JHM-D-14-0042.1.

Lin, Y., 2011: GCIP/EOP surface: Precipitation NCEP/EMC 4KM Gridded Data (GRIB) Stage IV data, version 1.0. UCAR/ NCAR Earth Observing Laboratory, accessed 21 June 2017, https://data.eol.ucar.edu/dataset/21.093. 
Maggioni, V., P. C. Meyers, and M. D. Robinson, 2016: A review of merged high-resolution satellite precipitation product accuracy during the Tropical Rainfall Measuring Mission (TRMM) era. J. Hydrometeor., 17, 1101-1117, https://doi.org/10.1175/ JHM-D-15-0190.1.

McBride, J. L., and E. E. Ebert, 2000: Verification of quantitative precipitation forecasts from operational numerical weather prediction models over Australia. Wea. Forecasting, 15, 103-121, https:// doi.org/10.1175/1520-0434(2000)015<0103:VOQPFF>2.0.CO;2.

Mlawer, E. J., S. J. Taubman, P. D. Brown, M. J. Iacono, and S. A. Clough, 1997: Radiative transfer for inhomogeneous atmospheres: RRTM, a validated correlated-k model for the longwave. J. Geophys. Res., 102, 16 663-16 682, https://doi.org/ 10.1029/97JD00237.

Monin, A. S., and A. M. Obukhov, 1954: Basic laws of turbulent mixing in the surface layer of the atmosphere (in Russian). Tr. Geofiz. Inst., Akad. Nauk SSSR, 24, 163-187.

Nazaripour, H., and M. R. M. Daneshvar, 2017: Rain gauge network evaluation and optimal design using spatial correlation approach in arid and semi-arid regions of Iran. Theor. Appl. Climatol., 129, 1255-1261, https://doi.org/10.1007/s00704-016-1853-3.

NCEP, 2015: NCEP GDAS/FNL 0.25 degree global tropospheric analyses and forecast grids. NCAR CISL Research Data Archive, accessed 21 June 2017, https://doi.org/10.5065/ D65Q4T4Z.

Nelson, B. R., O. P. Prat, D.-J. Seo, and E. Habib, 2016: Assessment and implications of NCEP Stage IV quantitative precipitation estimates for product intercomparisons. Wea. Forecasting, 31, 371-394, https://doi.org/10.1175/WAF-D-14-00112.1.

Nikolopoulos, E. I., N. S. Bartsotas, E. N. Anagnostou, and G. Kallos, 2015: Using high-resolution numerical weather forecasts to improve remotely sensed rainfall estimates: The case of the 2013 Colorado flash flood. J. Hydrometeor., 16, 1742-1751, https://doi.org/10.1175/JHM-D-14-0207.1.

O, S., U. Foelsche, G. Kirchengast, J. Fuchsberger, J. Tan, and W. A. Petersen, 2017: Evaluation of GPM IMERG Early, Late, and Final rainfall estimates using WegenerNet gauge data in southeastern Austria. Hydrol. Earth Syst. Sci., 21, 6559-6572, https://doi.org/10.5194/hess-21-6559-2017.

Peel, M. C., B. L. Finlayson, and T. A. McMahon, 2007: Updated world map of the Koppen-Geiger climate classification. $H y$ drol. Earth Syst. Sci., 11, 1633-1644, https://doi.org/10.5194/ hess-11-1633-2007.

PRISM Climate Group, 2018: PRISM climate data. Oregon State University, accessed 26 March 2018, http://www.prismclimate.org.

Sapiano, M. R. P., and P. A. Arkin, 2009: An intercomparison and validation of high-resolution satellite precipitation estimates with 3-hourly gauge data. J. Hydrometeor., 10, 149-166, https://doi.org/10.1175/2008JHM1052.1.

Sharifi, E., R. Steinacker, and B. Saghafian, 2016: Assessment of GPM-IMERG and other precipitation products against gauge data under different topographic and climatic conditions in Iran: Preliminary results. Remote Sens., 8, 135, https://doi.org/ 10.3390/rs8020135.

Siddique, R., A. Mejia, J. Brown, S. Reed, and P. Ahnert, 2015: Verification of precipitation forecasts from two numerical weather prediction models in the middle Atlantic region of the USA: A precursory analysis to hydrologic forecasting. J. Hydrol., 529, 1390-1406, https://doi.org/10.1016/j.jhydrol.2015.08.042.

Smalley, M., T. L'Ecuyer, M. Lebsock, and J. Haynes, 2014: A comparison of precipitation occurrence from the NCEP
Stage IV QPE product and the CloudSat cloud profiling radar. J. Hydrometeor., 15, 444-458, https://doi.org/10.1175/JHM-D13-048.1.

Tang, G., Y. Ma, D. Long, L. Zhong, and Y. Hong, 2016a: Evaluation of GPM Day-1 IMERG and TMPA version-7 legacy over mainland China at multiple spatiotemporal scales. J. Hydrol., 533, 152-167, https://doi.org/10.1016/j.jhydrol.2015.12.008.

_, Z. Zeng, D. Long, X. Guo, B. Yong, W. Zhang, and Y. Hong, 2016b: Statistical and hydrological comparisons between TRMM and GPM level-3 products over a midlatitude basin: Is Day-1 IMERG a good successor for TMPA 3B42V7? J. Hydrometeor., 17, 121-137, https://doi.org/10.1175/JHM-D-15-0059.1.

Thompson, G., P. R. Field, R. M. Rasmussen, and W. D. Hall, 2008: Explicit forecasts of winter precipitation using an improved bulk microphysics scheme. Part II: Implementation of a new snow parameterization. Mon. Wea. Rev., 136, 5095-5115, https://doi.org/10.1175/2008MWR2387.1.

Tiedtke, M., 1989: A comprehensive mass flux scheme for cumulus parameterization in large-scale models. Mon. Wea. Rev., 117, 1779-1800, https://doi.org/10.1175/1520-0493(1989)117<1779: ACMFSF $>2.0 . \mathrm{CO} ; 2$.

Vidale, P. L., D. Lüthi, C. Frei, S. I. Seneviratne, and C. Schär, 2003: Predictability and uncertainty in a regional climate model. J. Geophys. Res., 108, 4586, https://doi.org/10.1029/ 2002JD002810.

Villarini, G., and W. F. Krajewski, 2007: Evaluation of the research version TMPA three-hourly $0.25^{\circ} \times 0.25^{\circ}$ rainfall estimates over Oklahoma. Geophys. Res. Lett., 34, L05402, https:// doi.org/10.1029/2006GL029147.

Wen, Y., A. Behrangi, B. Lambrigtsen, and P.-E. Kirstetter, 2016: Evaluation and uncertainty estimation of the latest radar and satellite snowfall products using SNOTEL measurements over mountainous regions in western United States. Remote Sens. 8, 904, https://doi.org/10.3390/rs8110904.

Xie, P., M. Chen, S. Yang, A. Yatagai, T. Hayasaka, Y. Fukushima, and C. Liu, 2007: A gauge-based analysis of daily precipitation over East Asia. J. Hydrometeor., 8, 607-626, https://doi.org/ 10.1175/JHM583.1.

Yong, B., B. Chen, Y. Tian, Z. Yu, and Y. Hong, 2016: Errorcomponent analysis of TRMM-based multi-satellite precipitation estimates over mainland China. Remote Sens., 8 , 440, https://doi.org/10.3390/rs8050440.

Zhang, C., Y. Wang, and K. Hamilton, 2011: Improved representation of boundary layer clouds over the southeast Pacific in ARW-WRF using a modified Tiedtke cumulus parameterization scheme. Mon. Wea. Rev., 139, 3489-3513, https://doi.org/ 10.1175/MWR-D-10-05091.1.

Zhang, J., and Coauthors, 2016: Multi-Radar Multi-Sensor (MRMS) quantitative precipitation estimation: Initial operating capabilities. Bull. Amer. Meteor. Soc., 97, 621-638, https://doi.org/10.1175/BAMS-D-14-00174.1.

Zhang, X., E. N. Anagnostou, M. Frediani, S. Solomos, and G. Kallos, 2013: Using NWP simulations in satellite rainfall estimation of heavy precipitation events over mountainous areas. J. Hydrometeor., 14, 1844-1858, https://doi.org/10.1175/ JHM-D-12-0174.1.

,,-- and H. Vergara, 2016: Hydrologic evaluation of NWPadjusted CMORPH estimates of hurricane-induced precipitation in the southern Appalachians. J. Hydrometeor., 17, 1087-1099, https://doi.org/10.1175/JHM-D-15-0088.1. 